\title{
PATH DEPENDENCE REPETITION \\ DINAMIKA PERKEMBANGAN PARTAI PROTO \\ ISLAM INDONESIA, \\ SAREKAT ISLAM (1911-1940)
}

\section{Agus Riyanto}

\section{Mahasiswa Program Doktor Ilmu Politik UGM Yogyakarta}

\begin{abstract}
This article aims to describe the trajectory of the development of Sarekat Islam (SI) in the pre-independence era by using path dependence analysis and critical junctures. In this context, important political decisions made by the proto-Islamic party agents will identify various alternatives determined by their antecedent conditions, as well as a series of follow-up causal events after critical junctures as path dependence patterns that lead to an outcome or outcome of the development of the SI organization. explained that there were three stages of the development of the Sarekat Islam organization, which transformed into the Sarekat Islam Party (PSI) and the Indonesian Sarekat Islam Party (PSII) which were produced by three agent decisions in moments of critical juntures, namely the stages of growth, division and decline.
\end{abstract}

Key word : Critical junctures, Path dependence, the proto- Islamic party

\section{A. PENDAHULUAN}

Eksistensi partai Islam di Indonesia telah memiliki akar historis panjang dengan lahirnya partai proto berbasis Islam sejak pra kemerdekaan pada awal abad ke 20. Istilah partai proto ini diadopsi dari konsepsi Amal terkait tipologi partai politik yang didefinisikan sebagai tipe awal partai politik sebelum menjadi suatu partai modern. ${ }^{1}$ Tercatat ada tiga partai proto Islam yang lahir

\footnotetext{
${ }^{1}$ Ichlasul Amal membagi lima jenis partai berdasar tingkat komitmennya terhadap ideologi dan kepentingan yaitu 1) Partai Proto, 2) Partai Kader, 3) Partai Massa, 4)Partai Diktatorial, serta 5) Partai Catch-All. Lihat Ichlasul Amal, "Pengantar", dalam Ichlasul Amal (editor), Teori-Teori Mutakhir Partai Politik (Yogyakarta: PT.Tiara Wacana, 1988), hal.xv.
} 
pada era ini. Pertama, Sarekat Dagang Islam (SDI) yang berdiri tahun 1911 di Surakarta kemudian bertransformasi menjadi Sarekat Islam (SI) tahun 1912, Partai Sarekat Islam (PSI) tahun 1923, dan akhirnya menjadi Partai Sarekat Islam Indonesia (PSII) tahun $1930 .^{2}$ Kedua, Partai Muslimin Indonesia atau PMI didirikan tahun 1930 di Sumatera Barat dan bertransformasi menjadi PERMI tahun 1932 yang berkembang di sebagaian Sumatera. ${ }^{3}$ Ketiga, Partai Islam Indonesia (PII) yang berdiri tahun 1938 dari konflik internal di Partai Sarikat Islam Indonesia (PSII). ${ }^{4}$

Namun artikel ini hanya akan menjelaskan perkembangan SI didasarkan dua argument. Pertama; SI merupakan personifikasi partai proto Islam paling awal yang kemudian memicu dan memotivasi kemunculan organisasi pergerakan nasional berbasis agama lainnya. Kedua, SI berhasil menjadi kekuatan dominan dan determinan pada era ini, yang keanggotaannya tidak hanya di lingkup Jawa an sich tetapi juga di Kepulauan Nusantara lainnya.

Berbeda dengan kajian-kajian terdahulu tentang SI seperti Korver, ${ }^{5}$ Noer, ${ }^{6}$ Timur Djaelani, ${ }^{7}$ Rahardjo, ${ }^{8}$ maupun Nasihin $;{ }^{9}$ artikel ini menggunakan pendekatan institusionalisme historis yaitu alat analisis path dependence dan critical junctures yang mengkaitkan perkembangan organisasi SI dengan keputusan agen di masa lalu. Kerangka analisa yang digunakan adalah step-wise critical juncture and path dependence repetition model yang ditawarkan oleh Choia dan kawan-kawan dengan empat

\footnotetext{
${ }^{2}$ Deliar Noer, Gerakan Modern Islam di Indonesia 1900-1942 (Jakarta :LP3ES, 1980), hal. 114-170

3 Untuk ulasan mengenai PERMI lihat, Taufik Abdullah, Sekolah dan Politik : Pergerakan Kaum Muda di Sumatra Barat, 1927-1933 (Yogyakarta : Suara Muhammadiyah, 2018) dan Deliar Noer, Gerakan Modern Islam di Indonesia 1900-1942, hal. 170-174.

${ }^{4}$ Deliar Noer, Gerakan Modern Islam di Indonesia 1900-1942, hal. 170-179.

${ }^{5}$ A.P.E Korver, Gerakan Ratu Adil ?, terjemahan Grafitipers, (Jakarta : PT. Grafitipers,1985).

${ }^{6}$ Deliar Noer, Gerakan Modern Islam di Indonesia 1900-1942,

7 Anton Timur Jaelani, Gerakan Sarekat Islam : Kontribusinya pada Nasionalisme Indonesia,terjemahan Gordon B Manuain, (Jakarta : LP3ES, 2017).

${ }^{8}$ Handri Raharjo, Metamorfosis Sarekat Islam : Gerakan Politik Islam dan Munculnya Kesadaran Nasional (Yogyakarta : Media Pressindo, 2019),

${ }^{9}$ Nasihin, Sarekat Islam Mencari Ideologi 1924-1945, (Yogyakarta : Pustaka Pelajar, 2012).
} 
karakteristik yaitu situasi kontingensi, durasi critical juncture yang singkat, tersedianya alternatif-alternatif, dan adanya proses reinforcement dalam path dependence. ${ }^{10}$ Model tersebut dikombinasikan dengan konsepsi path dependence Mahoney yang menambahkan proses reactive sequences disamping self reinforcing sequences. ${ }^{11}$ Mahoney mendefinisikan critical junctures sebagai titik pilihan penting yang dibuat aktor atau agen dari alternatif-alternatif yang ditentukan peristiwa historis sebelumnya (kondisi antensenden) dan menentukan atau menutup hasil pada masa depan. ${ }^{12}$ Dalam konteks ini akan diidentifikasi momen-momen kritis (critical junctures) berupa keputusan politik yang dibuat agen dari berbagai alternatif yang ditentukan oleh kondisi antesendennya, serta serangkaian peristiwa kausal pasca critical junctures sebagai pola path dependence yang berujung kepada sebuah outcomes atau hasil perkembangan organisasi SI.

\section{B. METODE PENELITIAN}

Penelitian ini merupakan tipe penelitian kualitatif. Menurut Strauss dan Corbin penelitian kualitatif adalah penelitian yang tidak menghasilkan temuan melalui prosedur statistik atau formulasi hitungan lainnya. ${ }^{13}$ Sedangkan pendekatan penelitian yang digunakan adalah studi kasus yang dikombinasikan dengan pendekatan historis. Untuk proses pengumpulan data menggunakan teknik pengumpulan data dokumentasi dan rekaman arsip.

Penelitian ini dengan pendekatan studi kasus sebagaimana dikemukakan Creswell, menggunakan teknik analisa data deskripsi detail

\footnotetext{
${ }^{10}$ Chang Gyu Choia, Sugie Leeb, Heungsoon Kimb, Eun Yeong Seonga, "Critical Junctures and Path Dependence in Urban Planning and Housing Policy: A review of greenbelts and New Towns in Korea's Seoul Metropolitan Area", Land Use Policy, No. 80 (2019), hal. 195-204.

11 James Mahoney, "Path dependence in historical sociology", Theory Social. 29 (4), (2000), hal. 507-548.

12 James Mahoney, The Legacies of Liberalism : Path Dependence and Political Regime in Central America (John Hopkins University Press, 2001); kemudian "Path-dependent Explanations of Regime Change : Central Amerika in Comparative Perspective", Studies in Comparative International Development, Spring Vo. 16, No 1,(2001), hal, 111-141,

${ }^{13}$ Anselm Strauss dan Juliet Corbin, Dasar-Dasar Penelitian Kualitatif : Tata Langkaj dan Teknikteknik teorisasi data, terjemahan, (Yogyakarta : Pustaka Pelajar, 2003), hal. 4.
} 
tentang kasus tersebut dan menyertakan setting yang melingkupinya. ${ }^{14}$ Sementara dari alur analisa studi kasus mengacu Creswell meliputi lima tahapan pertama, mengorganisasikan data; kedua, membaca seluruh teks dan membuat catatan (memoring); ketiga, mendeskripsikan, mengklasifikasikan, dan menafsirkan data menjadi kode dan tema; keempat, menafsirkan data Kelima, menyajikan dan menvisualisasikan data. ${ }^{15}$

\section{HASIL DAN PEMBAHASAN}

Dinamika perkembangan Sarekat Islam (SI) terdiri dari tiga tahap yaitu pertumbuhan organisasi (1911-1921), tahap pembelahan (1916-1923), dan tahap kemosotan (1923-1940). Ketiga tahap tersebut merupakan outcome atau hasil yang terkait keputusan agen dalam momen critical juntures yang masing-masing menghasilkan rangkaian urutan peristiwa kausal sebagai sebuah proses path dependence.

\section{Periode Pertumbuhan Organisasi (1911 - 1921)}

Proses path dependence pertama lintasan perkembangan Sarekat Islam (SI) ditandai momen critical juncture pendirian Sarekat Dagang Islam (SDI) tahun 1911 di Surakarta oleh H. Samanhudi. SDI awalnya merupakan organisasi pedagang Muslim dan fokus kepada masalah-masalah ekonomi yang didirikan H. Samanhoedi, seorang pedagang batik di Surakarta, pada tahun 1911 (ada yang berpendapat tahun 1905). ${ }^{16}$ Tujuannya adalah memberikan proteksi terhadap kepentingan pedagang Muslim pribumi dari ekspansi dan supremasi pedagang-pedagang non pribumi khususnya China serta penetrasi bangsawan lokal yang mengganggu eksistensi ekonomi

\footnotetext{
14 John W. Creswell, Penelitian Kualitatif dan Desain Riset : Memilih diantara lima pendekatan, terjemahan (Yogyakarta : Pustaka Pelajar,2013), hal.277

${ }^{15}$ Ibid, hal.254-262

${ }^{16}$ Pendapat SDI didirikan H. Samanhoedi 16 Oktober 1905, dikemukakan antara lain Anton Timur Jaelani, Gerakan Sarekat Islam : Kontribusinya pada Nasionalisme Indonesia,terjemahan Gordon B Manuain, (Jakarta : LP3ES, 2017). Sementara pendapat SDI didirikan tahun 1911, antara lain Deliar Noer, Gerakan Modern Islam di Indonesia 1900 - 1942.
} 
mereka. ${ }^{17}$ Dalam beberapa studi disebutkan peran Tirto Adi Surdjo dalam proses pendirian SDI. ${ }^{18}$ Ia merupakan tokoh pergerakan nasional di Bogor dan pernah mendirikan Sarekat Prijaji. ${ }^{19}$ Namun organisasi tersebut tidak berumur panjang dan selanjutnya ia bergabung dengan Budi Utomo sebelum akhirnya mendirikan Sarekat Dagang Islamiyah di Bogor tahun 1909, ${ }^{20}$ menurut Noer tahun $1911 .^{21}$ Ketika berlangsung proses pendirian SDI, Tirto Adi Surdjo diminta Samanhudi ikut merumuskan anggaran dasar dan anggaran rumah tangga pada tahun $1911 .^{22}$

Momen critical juncture pertama ini tidak lepas dari dua antecendent conditions yang menentukan alternatif yang tersedia serta proses penyeleksian bagi para agen pergerakan Islam tersebut. Kondisi antesenden pertama adalah Kebijakan Etis yang diimplementasikan pemerintah kolonial Belanda sejak tahun 1901. Kebijakan tersebut diambil dalam rangka meningkatkan kesejahteraan kaum pribumi pasca pidato Ratu Wilhelmina di State General tahun 1901 yang menegaskan bahwa Belanda merasa mempunyai "kewajiban moral" terhadap rakyat Indonesia. ${ }^{23}$ Pidato ratu kemudian menjadi landasan kebijakan balas budi atau Kebijakan Etis, nama yang dipopulerkan P. Broooshooft dalam pamphlet De Ethische Koers in the Koloniale Politiek (Jalan Etis dalam Kebijakan Kolonial). ${ }^{24}$ Ada tiga bidang yang menjadi prioritas yaitu educatie (pendidikan), irrigatie (irigasi) dan emigratie (transmigrasi), sebuah trilogi yang dikenalkan oleh Van Deventer. $^{25}$

\footnotetext{
${ }^{17}$.Deliar Noer, Gerakan Modern Islam di Indonesia 1900 - 1942 , hal 115-116.

${ }^{18}$ Handri Raharjo, Metamorfosis Sarekat Islam : Gerakan Politik Islam dan Munculnya Kesadaran Nasional (Yogyakarta : Media Pressindo, 2019), 35-48.

19 Ibid, hal. 41.

${ }^{20}$ Ibid, hal 41

${ }^{21}$ Deliar Noer, Gerakan Modern Islam di Indonesia 1900 - 1942, hal. 116.

22 Ibid, hal 116.

${ }^{23}$ H. Aqib Suminto, Politik Islam Hindia Belanda (Jakarta : LP3ES, 1985), hal. 100.

${ }^{24}$ Anton Timur Djaelani, Gerakan Sarekat Islam; Kontribusinya pada nasionalisme Indonesia,

${ }^{25}$ Yudi Latif, Geneaologi Intelegensia : Pengetahuan dan Kekuasaan Intelegensia Muslim Abad XX, (Jakarta : Kencana Prenadamedia Group,2013), hal. 75.
} 
Kebijakan ini muncul dari adanya kritik pedas terkait kondisi sosial ekonomi pribumi yang menderita akibat Cultuurstelsel (tanam paksa) dan sistem ekonomi liberal yang diimplementasikan pemerintah kolonial. Salah satu pengritik kerasnya adalah C. Th. Van de Venter, pengacara Belanda yang menghabiskan beberapa tahun di Indonesia. Dalam artikelnya "Debt of Honour" (de Gids) tahun 1899, ia menegaskan bahwa orang-orang Belanda telah berutang kekayaan dan kemakmuran kepada orang-orang di Indonesia sehingga harus membayarnya dengan kebijakan yang berorientasi untuk kepentingan penduduk pribumi. Akhirnya pada tahun 1901 Ratu Wilhelmina mengumumkan sebuah investigasi terkait kesejahteraan di Jawa, dan menyetujui secara resmi Kebijakan Etis. ${ }^{26}$

Kondisi antesenden kedua adalah kemunculan kelas intelektual Muslim pada 1900-an. Peristiwa tersebut salah satu dampak positif dari kebijakan etis yang meskipun tidak serta merta memajukan kesejahteraan sosial dan ekonomi penduduk pribumi, namun di bidang edukasi berhasil menstimulus jumlah penduduk terdidik. Pada 1900, total penduduk pribumi yang tercatat mendaftar di lembaga pendidikan dari semua jenis dan level sekitar 101.003 penduduk dan meningkat hampir tiga kali lipat pada tahun 1910 yaitu 310.496 orang. ${ }^{27}$ Kebijakan Etis bidang edukasi ini juga mampu mendorong kemunculan kelas intelektual baru Muslim seiring masuknya pengaruh gerakan modernisme Islam dari Timur Tengah, khususnya pemikiran Muhammad Abduh (1849-1905). Gerakan tersebut tidak hanya menginspirasi kaum Muslim di Indonesia untuk memodernisasi pendidikan Islam tetapi juga menumbuhkan semangat nasionalisme berbasis agama. ${ }^{28}$ Ada banyak organisasi Islam yang berdiri dan mendirikan lembaga pendidikan seperti $A l$ -

\footnotetext{
${ }^{26}$ M.C.Ricfleks, A History of Modern Indonesia Since c. 1200, (USA : Palgrave Macmillan, 2008), hal. 193-194.

27 Ibid, hal 92.

${ }^{28}$ Anton Timur Djaelani, Gerakan Sarekat Islam; Kontribusinya pada nasionalisme Indonesia, hal. 28-30.
} 
Djami'at al- Chairijah atau Djami'at Choir, ${ }^{29}$ Al-Irsyad dengan tokoh utamanya Syeh Ahmad Soorkarti, ${ }^{30}$ Sekolah Thalawib di Sumatera Barat di bawah kepemimpinan Abdul Karim Amrullah atau Haji Rosul, ${ }^{31}$ Djalaludin Thaib, Zainuddin Labai al-Junusi di Padang Panjang, M. Djamil Djambek, Ibrahim Musa, dan Latif Syakur di Bukittinggi, serta M Thaib Umar dan Mahmud Yunus di Batusangkar yang membentuk Persatuan Guru-Guru Agama Islam (PGAI) pada tahun 1918, ${ }^{32}$ Pesantren Mambaul Ulum di Surakarta, ${ }^{33}$ serta Muhammadiyah di Yogyakarta. $^{34}$ Lingkungan kelembagaan ini mampu melahirkan kelas intelektual Muslim yang menjadi pelopor pergerakan nasional era kolonial.

Kedua kondisi antesenden tersebut kemudian menentukan kemunculan berbagai alternatif yang tersedia dalam momen critical junctures khususnya terkait metode perjuangan melawan kolonialisme antara tetap menggunakan cara konvensional seperti pergerakan bersenjata atau secara terorganisir melalui organisasi pergerakan modern, serta alternatif basis ideologi perjuangan yaitu antara berlandaskan Islam, nasionalisme, regionalisme, sosialisme atau bahkan marxisme.

Pasca critical juncture pertama muncul serangkaian urutan peristiwa lanjutan yang memiliki efek kausal dan mengarahkan kepada hasil atau outcome perkembangan organisasi tersebut. Ada sejumlah proses reactive sequences pasca momen tersebut atau periode the aftermath of critical junctures. Proses pertama muncul pada 12 Agustus 1912 ketika Residen Surakarta membekukan SDI. Namun pembekuan tersebut hanya sementara karena pada 26 Agustus 1912 dicabut kembali setelah SDI dianggap tidak

\footnotetext{
29 Deliar Noer, Gerakan Modern Islam di Indonesia 1900 - 1942, dan Yudi Latif, Geneaologi Intelegensia : Pengetahuan dan Kekuasaan Intelegensia Muslim Abad XX.

${ }^{30}$ Yudi Latif. Geneaologi Intelegensia : Pengetahuan dan Kekuasaan Intelegensia Muslim Abad XX, hal. 122.

${ }^{31}$ Deliar Noer, Gerakan Modern Islam di Indonesia 1900 - 1942, hal 52-53

32 Yudi Latif. Geneaologi Intelegensia : Pengetahuan dan Kekuasaan Intelegensia Muslim Abad XX, hal. 125.

33 Ibid, hal. 125.

34 Ibid, hal. 126.
} 
akan melakukan penentangan terhadap pemerintah kolonial, ${ }^{35}$ serta adanya persyaratan perubahan anggaran dasar bahwa organisasi tersebut hanya berskala lokal khusus Surakarta saja. ${ }^{36}$ Proses pembekuan dilatarbelakangi kekhawatiran terhadap perkembangan SDI ke daerah-daerah lain di Jawa sehingga aktivitas anggotanya tidak bisa diawasi penguasa setempat. Selain itu mereka juga dituduh memprovokasi konflik dengan komunitas pedagang China dan pemogokan pekerja di perkebunan Krapyak di Mangkunegaran. ${ }^{37}$

Merespon pembatasan tersebut, H.O.S Tjokroaminoto yang bergabung dalam organisasi itu bulan Mei 1912, kemudian diminta ikut mereformulasi statuta baru. Pada 10 September 1912 statuta baru SDI berhasil disusun dengan nama Sarekat Islam (SI) di bawah pimpinan Tjokroaminoto. Statuta ini mengelimir unsur politik sebagai strategi Tjokroaminoto agar tidak melanggar Peraturan Pemerintah 111 yang melarang organisasi dan pertemuan yang bersifat politik. Namun hal tersebut tidak menjadikan mereka diakui pemerintah kolonial. ${ }^{38}$ Dalam konteks path dependence reformulasi statuta organisasi dan transformasi SDI menjadi SI ini merupakan reactive sequences terkait kebijakan pembatasan oleh Residen Surakarta pada Agustus 1912. Keputusan tersebut diambil agar mereka mendapatkan legalitas dari pemerintah kolonial meskipun gagal.

Upaya memperoleh legalitas terus dilakukan elit politik SI. Pada 29 Maret 1913 beberapa Komite Pelaksana SI yang dipimpin H.O.S Tjokroaminoto mengadakan audiensi dengan Gubernur Jenderal Belanda Idenburg. Pemerintah kolonial Belanda tetap menolak melegalkan SI sebagai organisasi yang mencakup seluruh wilayah Jawa, namun memberikan peluang legalitas terhadap organisasi SI di wilayah-wilayah lokal. Keputusan ini ditetapkan pada 30 Juni 1913, No.3 dan diterbitkan dalam Javasche

\footnotetext{
${ }^{35}$ A.K. Pringgodigdo, Sejarah Pergerakan Rakyat Indonesia, ( Jakarta : PT Dian Rakyat, 1991), hal. 5

${ }^{36}$ Deliar Noer, Gerakan Modern Islam di Indonesia 1900 - 1942, hal. 117.

37 Ibid, hal. 117.

${ }^{38}$ Anton Timur Djaelani, Gerakan Sarekat Islam; Kontribusinya pada nasionalisme Indonesia, hal 38.
} 
Courant 15 Juli $1913 .{ }^{39}$ Peluang tersebut kemudian dimanfaatkan cabangcabang Sarekat Islam di daerah. Pada tahun 1914 terdapat 56 jumlah cabang SI yang diakui legalitasnya. ${ }^{40}$ Upaya cabang-cabang SI tersebut merupakan rangkaian reactive sequences dalam rangka menyiasati setting kelembagaan politik yang membatasi gerak mereka sejak Agustus 1912.

Kebijakan pemerintah kolonial yang hanya melegalisasi SI di tingkat cabang telah menyebabkan rasa ketidakpuasan pemimpin organisasi tersebut. Agar tetap bisa melakukan konsolidasi dengan cabang-cabang SI lokal, para elit SI pada 18 Februari 1914 sepakat membentuk pengurus pusat Sarekat Islam, ${ }^{41}$ atau Komite Sentral Sarekat Islam (CSI). ${ }^{42}$ Komite tersebut dimodifikasi menjadi Sarekat Islam Pusat atau CSI dan difungsikan sebagai Badan Pengurus Pusat, ${ }^{43}$ dengan ketua H.O.S Tjokroaminoto dan Gunawan sebagai wakil ketua, sedangkan H. Samanhudi menjadi ketua kehormatan. ${ }^{44}$ Upaya pimpinan SI ini mengindikasikan reactive sequences pasca kebijakan pemerintah kolonial hanya memberikan legalitas kepada cabang-cabang SI.

Tahun 1916 terjadi perubahan kebijakan pemerintah kolonial terhadap eksistensi organisasi SI. Para tokoh SI kembali mengajukan permohonan legalitas, meskipun ada pro kontra di antara elit kolonial, ${ }^{45}$ Gubernur Jenderal Idenburg melalui keputusan pemerintah tanggal 18 Maret 1916, No 41 yang dipublikasikan dalam Javasche Courant no.25 akhirnya mengakui legalitas

\footnotetext{
${ }^{39} \mathrm{lbid}$, hal. 48.

${ }^{40}$ lbid, hal. 50

${ }^{41}$ Deliar Noer, Gerakan Modern Islam di Indonesia 1900 - 1942, hal, 119.

42 Dalam versi lain Raharjo menyebut pembentukan CSI pada konggres di Yogyakarta 18 sampai 20 April 1914, lihat Handri Rahardjo, Metamorfosis Sarekat Islam : Gerakan Politik Islam dan Munculnya Kesadaran Nasional, hal, 72. Hal yang sama dikemukakan A.P.E, Korver, Sarekat Islam Gerakan Ratu Adil ?, hal.35. Sementara Djaelani menyebutkan CSI dibentuk tahun 1915 lihat Anton Timur Djaelani, Gerakan Sarekat Islam; Kontribusinya pada nasionalisme Indonesia, hal 52.

${ }^{43}$ Anton Timur Djaelani, Gerakan Sarekat Islam; Kontribusinya pada nasionalisme Indonesia, hal 52.

${ }^{44}$ Deliar Noer, Gerakan Modern Islam di Indonesia 1900 - 1942, hal, 119.

45 Salah satu elit Belanda yang mendukung pemberian legalitas SI adalah penasehat MasalahMasalah Bumiputera, D.Rinkes, meskpiun oleh Korver sikap Rinkes lebih dilihat sebagai sikap yang pragmatis. Lihat Deliar Noer, hal 205 dan APE. Korver, Sarekat Islam Gerakan Ratu Adil ?, hal 26.
} 
CSI atau Komite Sentral Sarekat Islam. ${ }^{46}$ Dalam konteks path dependence, pengakuan legalitas SI ini merupakan outcome dari rangkaian urutan peristiwa yang bersifat kausal pasca momen critical juncture yang ditandai proses reactive sequences. Pengakuan ini membawa implikasi positif terhadap perkembangannya organisasi SI. Pada tahun 1916, pasca Konggres Nasional I, SI berhasil meneguhkan sebagai organisasi pergerakan nasional terbesar dan berskala nasional. ${ }^{47}$

\section{Periode Pembelahan Organisasi (1921-1923)}

Periode perkembangan Serekat Islam kedua ditandai momen critical juncture penetapan kebijakan displin dalam Konggres Nasional SI keenam Oktober tahun 1921 di Surabaya. Konggres yang tidak dihadiri Tjokroaminoto karena masih ditahan Belanda, memutuskan larangan keanggotaan ganda bagi anggota SI. Agus Salim dengan dukungan Abdoel Moeis merupakan tokoh penggagas penerapan disiplin partai untuk mengelimir unsur-unsur komunisme di tubuh SI. ${ }^{48}$ Kebijakan ini diputuskan melalui perdebatan sengit diantara tokoh SI yang berhaluan komunis dengan kubu Agus Salim-Moeis yang berhasil unggul. ${ }^{49}$

Kebijakan dalam momen critical juncture tersebut tidak lepas dari dua kondisi antesenden yang menentukan alternatif-alternatif serta proses penyeleksian bagi agen partai proto Islam ini. Kondisi antesenden pertama terkait lingkungan kelembagaan (institutional environment) berkembangnya sosialisme di Hindia Belanda sejak tahun awal abad ke 20. Perkembangan tersebut tidak lepas dari peran Hendricus Josephus Franciscus Marie Sneevliet, mantan Ketua Serikat Buruh Kereta Api atau NVSTP di bawah

\footnotetext{
${ }^{46}$ Anton Timur Djaelani, Gerakan Sarekat Islam; Kontribusinya pada nasionalisme Indonesia, hal 52.

${ }^{47}$ Handri Raharjo, Metamorfosis Sarekat Islam : Gerakan Politik Islam dan Munculnya Kesadaran Nasional,hal. 78

${ }^{48}$ George Mc Turnan Kahin, Nasionalisme dan Revolusi Indonesia, terjemahan Tim Komunitas Bambu (Jakarta : Komunitas Bambu, 2013), hal 106

${ }^{49}$ Deliar Noer, Gerakan Modern Islam di Indonesia 1900 - 1942, hal 140
} 
kendali politik SDAP (Sociaal Democratische Arbeiders Partij) atau Partai Buruh Sosial Demokrat Belanda. Sneevliet berkunjung ke Jawa tahun 1913, ${ }^{50}$ dan bekerja sebagai staf editorial surat kabar milik sindikat perusahaan gula di Surabaya yaitu Soerabajaasch Handelsblad. Kemudian ia dipilih rekan sosialisnya D.M. G Koch menggantikan posisinya sebagai sekretaris asosiasi dagang di Semarang yaitu Semarang Handelsvereniging. ${ }^{51}$ Di kota ini Sneevliet mempropagandakan ideologi sosialisnya dan mampu mempengaruhi organisasi tersebut menjadi semakin radikal. Untuk lebih mengefektifkan penyebaran ideologi sosialisme, Sneevliet bersama 60 (enam puluh) tokoh sosial demokrat lainnya membentuk Indische SociaalDemocratische Vereniging (ISDV) pada 9 Mei 1914 di Surabaya. ${ }^{52}$ ISDV juga menjalin aliansi dengan Insulinde, organisasi berorientasi kelompok Eurasia (Indo-Eropa) yang berdiri tahun 1907. Namun kerjasama itu tidak berlangsung lama karena ISDV menilai tokoh-tokoh Insulinde bersifat oportunistik. Pada konggres 1916, ISDV memutuskan aliansinya dengan Insulinde dan memalingkan kepada SI. ${ }^{53}$

Kondisi antesenden kedua adalah kehadiran unsur-unsur kiri ke dalam SI akibat infiltrasi gerakan komunisme oleh ISDV pasca kegagalan mereka dengan Insulinde. Sneevliet berusaha membangun relasi bersama SI dengan mendidik anggota muda potensial organisasi ini ide-ide sosialisme revolusioner. Salah satu tokoh yang sukses dididik adalah Semaun, anggota SI di cabang Surabaya sejak 1914 dan kemudian menjadi sekretaris. Semaun bergabung menjadi anggota ISDV cabang Surabaya tahun 1915, namun tetap merangkap anggota SI. Pada tahun 1916 Semaun dipercaya menjadi wakil ketua cabang ISDV Surabaya. ${ }^{54}$

\footnotetext{
${ }^{50}$ A.K. Pringgodigdo, Sejarah Pergerakan Rakyat Indonesia, hal. 14.

${ }^{51}$ Ruth T. Mcvey, Kemunculan Komunisme Indonesia, terjemahan Tim Komunitas Bambu (Jakarta: Komunitas Bambu, 2010), hal. 20

52 Ibid, hal 21-22.

53 Ibid, hal. 26-28

54 Ibid, hal. 32
} 
ISDV juga berusaha menjajagi aliansi secara organisatoris dengan SI, tetapi pada konggres SI tahun 1916 di Surabaya tidak mendapat respon serius. Meskipun demikian sifat revolusioner mulai berkembang ke dalam SI ditandai tumbuhnya sikap anti pemerintah serta wacana pembauran prinsipprinsip Islam dan sosialisme. ${ }^{55}$ Infiltrasi paham sosialisme Marxisme semakin masif pasca Semaun menjadi Ketua SI cabang Semarang. Kahin mencatat menjelang 1917 muncul arah yang semakin revolusioner dalam tubuh SI dengan dua tokohnya Semaun dan Darsono sebagai juru bicara utama. ${ }^{56}$

Infiltrasi tidak hanya merasuki cabang SI di Semarang, beberapa cabang SI di Jakarta, Surabaya dan Surakarta juga menjadi tempat subur perkembangan ideologi kiri tersebut. Para tokoh SI lain seperti Alimin dan Muso dari cabang Jakarta maupun Haji Misbah dari cabang Surakarta juga tertarik dengan ide-ide revolusioner ISDV. ${ }^{57}$ Infiltrasi semakin kuat meskipun Sneevliet ditangkap dan diasingkan pemerintah kolonial tahun 1918, karena para propenen marxis di ISDV sepakat berubah menjadi Partii der Kommunisten in Indie (Partai Komunis di Indies) yang disingkat PKI pada tanggal 23 Mei $1920 .{ }^{58}$ Dua tokoh SI cabang Semarang yaitu Semaun ditunjuk menjadi ketua sedangkan Darsono menjadi wakilnya. Keduanya sengaja mempertahankan keanggotaannya di SI agar lebih efektif menginfiltrasi. ${ }^{59}$ Intensitas infiltrasi ideologi komunis ke tubuh SI yang semakin meningkat menyebabkan munculnya resistensi dari tokoh CSI antara lain Abdoel Moeis, Agus Salim, dan Sosrokardono. ${ }^{60}$ Menghadapi inflitrasi tersebut, Tjokroaminonto cenderung kompromistis demi mempertahankan koherensi partai. Sebaliknya Moeis dan kawan-kawan bersikap resisten dan berusaha memperjuangkan penegakan disiplin partai yaitu melarang

55 Ibid, hal. 29

${ }^{56}$ George Mc Turnan Kahin, Nasionalisme dan Revolusi Indonesia, hal, 100.

${ }^{57}$ Yudi Latif, Geneaologi Intelegensia : Pengetahuan dan Kekuasaan Intelegensia Muslim Abad XX, hal. 188.

${ }^{58}$ George Mc Turnan Kahin, Nasionalisme dan Revolusi Indonesia, hal. 104.

${ }^{59}$ Anton Timur Djaelani, Gerakan Sarekat Islam : Kontribusinya pada Nasionalisme Indonesia, hal 73.

${ }^{60}$ Deliar Noer, Gerakan Modern Islam di Indonesia 1900 - 1942, hal 137. 
keanggotaan ganda serta pengeluaran orang-orang komunis dari SI. ${ }^{61}$ Infiltrasi ideologi marxisme ke tubuh SI ini merupakan kondisi antesenden kedua yang menentukan munculnya alternatif kebijakan antara membiarkan anggota SI merangkap anggota ISDV yang bertransformasi menjadi PKI, atau menegakkan disiplin partai. Dua opsi inilah yang kemudian diperdebatkan pada konggres keenam SI tahun 1921 dan dimenangkan kelompok Agus Salim dan Abdoel Moeis untuk memutuskan kebijakan disiplin partai yang melarang keanggotaan ganda. ${ }^{62}$

Kebijakan tersebut kemudian memicu serangkaian urutan peristiwa berikutnya yaitu reactive sequences. Pasca konggres tahun 1921, cabangcabang SI Semarang dan sekitarnya yang sudah terinfiltrasi ideologi komunis satu per satu memisahkan diri dari CSI. Puncaknya dalam Konggres PKI di Semarang 25 Desember 1921, mereka sepakat membentuk "Persatuan Sarekat Islam" atau di kenal dengan "SI Merah". ${ }^{63}$ Pembentukan tersebut menandai pecahnya koherensi partai proto Islam ini menjadi dua kubu yaitu CSI atau SI dan Persatuan Sarekat Islam atau SI Merah.

Pendirian SI Merah tahun 1921 mendorong reactive sequence lainnya yaitu keputusan mendirikan seksi-seksi Sarekat Islam Merah di daerahdaerah yang memiliki cabang SI dalam konggres PKI tahun 1923. Unit-unit yang dikuasai kubu komunis tersebut kemudian diganti menjadi Sarekat Rakyat dan diakui sebagai "dasar Partai Komunis dalam masyarakat". ${ }^{4}$ Dalam perkembangannya Sarekat Rakyat ini dibubarkan dalam Konggres PKI tahun 1924 karena anggotanya dianggap banyak dari kaum nasionalis borjouis yang tidak bisa dipercaya. ${ }^{65}$

Pecahnya koherensi SI pada tahun 1921 dengan pendirian SI Merah disusul upaya pembentukan Sarekat Rakyat di cabang-cabang SI tahun 1923

\footnotetext{
61 Ibid, hal. 139

62 Deliar Noer, Gerakan Modern Islam di Indonesia 1900 - 1942, hal 140

${ }^{63}$ Anton Timur Djaelani, Gerakan Sarekat Islam : Kontribusinya pada Nasionalisme Indonesia, hal 94

${ }^{64}$ George Mc Turnan Kahin, Nasionalisme dan Revolusi Indonesia, hal 108

65 Ibid, hal 109.
} 
berimplikasi terhadap kemerosotan kekuatan politik organisasi tersebut. Pada konggres nasional ketujuh tahun 1923 ketika jumlah cabang SI yang hadir berkurang dari 50 cabang pada konggres kelima menjadi 40, sedangkan delegasi yang hadir hanya sekitar 1.200 sampai 1.500 anggota. ${ }^{66}$ Kemorosotan ini dari perspektif path dependence merupakan hasil atau outcomes dari proses reactive sequences yang dipicu momen critical junctures kebijakan disiplin partai tahun 1921.

\section{Periode Kemerosotan (1921-1940)}

Periode path dependence ketiga diwarnai critical juncture yaitu kebijakan politik Hijrah yang diputuskan pada konggres nasional SI ketujuh tahun 1923. Selain memutuskan transformasi sikap dari kooperasi menjadi non kooperasi terhadap pemerintah kolonial, konggres itu juga memutuskan CSI menjadi Partai Syarikat Islam (PSI). ${ }^{67}$ Alternatif-alternatif dalam critical juncture ini tidak lepas dari dua kondisi antesenden yaitu munculnya perlawanan dari organisasi pergerakan nasional terhadap sindikat gula (suiker syndicat) yang berkontribusi mendorong kondisi antesenden kedua tindakan represif pemerintah kolonial terhadap SI.

Tahun 1918 merupakan titik balik perjuangan SI dengan munculnya upaya resistensi terhadap pemerintah kolonial Belanda. Pada 1918 dan 1919 melalui Volksraad, dewan rakyat yang dibentuk pemerintah kolonial, Tjokroaminoto gencar melakukan upaya reformasi kebijakan industrialisasi gula dengan mengusulkan pengurangan $50 \%$ dan $25 \%$ tanah perkebunan kebun yang digunakan untuk keperluan industri gula milik pemerintah karena melihat kondisi perekonomian rakyat pribumi yang semakin menderita. ${ }^{68}$ Meskipun usulan ini ditolak Volksraad namun menimbulkan reaksi keras dari

\footnotetext{
${ }^{66}$ Anton Timur Djaelani, Gerakan Sarekat Islam : Kontribusinya pada Nasionalisme Indonesia, hal, 103.

${ }^{67}$ Ibid, hal 105.

${ }^{68}$ Nasihin, Sarekat Islam Mencari Ideologi 1924-1945, (Yogyakarta : Pustaka Pelajar, 2012) hal. 108
} 
pemerintah kolonial yang kebijakannya dikendalikan oleh para sindikat gula (Suiker Syndicat). Usulan tersebut juga melahirkan kekhawatiran kelompok pemodal perkebunan gula atau sindikat gula yang tergabung dalam PEB ( Personil Economic Bond). ${ }^{69}$ Dalam rangka menekan reaksi anggota SI tersebut, PEB kemudian membuat organ-organ gerakan rakyat tandingan antara lain Sarekat Hedjo (Idjo) di Cianjur dan Sumedang, Pamitran di Bandung, Sarekat Pompa di Cimahi, Tolak Bahla Towil Umur (TBTO) di Tasikmalaya, dan Garut, kemudian Jamiatul Hasanah, Jamiatul Mutiiin, dan Ahlu Sunnah Wal Jamaah. ${ }^{70}$ Namun keberadaan organ-organ tersebut justru mendorong rakyat bumiputera semakin berani melakukan perlawanan. Berbagai aksi kekerasan terjadi, seperti Toli-Toli di Sulawesi Tengah pada Juni 1919 yang berujung kerusuhan dan terbunuhnya kontrolir Belanda J.P de Kat Angelino serta beberapa pembantunya dari penduduk pribumi. Pasca aksi tersebut Abdoel Moeis ditangkap Belanda atas tuduhan dalang kerusuhan. ${ }^{71}$ Selain itu muncul peristiwa berdarah di Cimareme Jawa Barat pada 7 Juli 1919, yaitu ketika seorang tokoh bernama Haji Hasan menolak menyerahkan padi dalam jumlah yang ditentukan kepada pemerintah Kolonial yang berujung tindakan represif dan memakan korban jiwa. Dalam kasus ini SI dituduh terlibat secara organisatoris. ${ }^{72}$

Sikap konfrontatif SI terkait kebijakan industrialisasi gula memicu kondisi antesenden kedua yaitu sikap pemerintah kolonial Belanda yang represif. Noer mencatat berbagai tindakan represif oleh Gubernur Jenderal van Limburg Stirum, serta pihak-pihak lain di kalangan Belanda terhadap SI. Organisasi ini dituduh memprovokasi rakyat melakukan pemberontakan dan pembunuhan terhadap orang Belanda sehingga dilakukan penangkapan

\footnotetext{
69 Ibid, hal 108-109.

70 Ibid, hal 109-110 dan Deliar Noer, Gerakan Modern Islam di Indonesia 1900-1942, hal. 219.

${ }^{71}$ Nasihin, Sarekat Islam Mencari Ideologi 1924-1945, hal. 109-110.

72 Ibid, hal.11-112,Deliar Noer, Gerakan Modern Islam di Indonesia 1900-1942, hal. 215 dan Anton Timur Djaelani, Gerakan Sarekat Islam : Kontribusinya pada Nasionalisme Indonesia, hal 67.
} 
terhadap anggota-anggota SI. Selain itu rapat-rapat SI juga dipersulit oleh pejabat Kolonial. ${ }^{73}$

Pada tahun 1921 Gubernur Jenderal Dirk Fork pengganti van Linburg Stirum memandang berbagai aksi rakyat yang terjadi mengganggu rust en orde (keamanan dan ketertiban) dan dianggap merongrong eksistensi pemerintah kolonial. Ia kemudian membentuk satuan khusus (intel) yang bertugas mengamankan serta menindak penduduk pribumi yang dianggap membahayakan rust en orde (keamanan dan ketertiban). Dirk Fork juga mencabut vergadering sehingga rakyat Indonesia tidak leluasa beraktivitas. ${ }^{74}$ Dan puncaknya pada tahun 1921 Tjokroaminoto, pemimpin utama SI, ditahan selama delapan bulan antara tahun 1921 sampai 1922, karena dituduh memberikan keterangan palsu dalam pengadilan kasus Sosrokardono. ${ }^{75}$ Kedua kondisi antesenden kedua tersebut menentukan kemunculan alternatif-alternatif dalam momen critical juncture tahun 1923.

Pasca keputusan politik Hijrah kemudian memicu rangkaian urutan peristiwa lanjutan yang ditandai reinforcement atau self-reinforcing sequences. Kebijakan itu di- reinforcement dalam Konggres PSI bulan Agustus tahun 1924 di Surabaya yang menyatakan penarikan diri dari Volksraad serta melarang anggotanya berhubungan dengan lembaga tersebut kecuali melalui anggota oposisi. ${ }^{76}$ Keputusan ini didasari oleh tidak responsifnya Pemerintah Kolonial Belanda terhadap tuntutan pengangkatan kembali Tjokroaminoto sebagai anggota Volksraad. ${ }^{77}$

Pada tahun 1927 kebijakan politik Hijrah kembali diperkuat ketika Tjokroaminoto menolak tawaran Pemerintah Belanda untuk menjadi anggota Volksraad. ${ }^{78}$ Dalam konggres di Pekalongan 14-17 Januari 1927 juga ditandai

\footnotetext{
73 Deliar Noer, Gerakan Modern Islam di Indonesia 1900-1942, hal. 214.

${ }^{74}$ Nasihin, Sarekat Islam Mencari Ideologi 1924-1945, hal 115.

75 Ibid, hal 116, Deliar Noer, Gerakan Modern Islam di Indonesia 1900-1942, hal 218, dan Anton Timur Djaelani , Gerakan Sarekat Islam : Kontribusinya pada Nasionalisme Indonesia, hal 67

${ }^{76}$ Deliar Noer, Deliar Noer, Gerakan Modern Islam di Indonesia 1900, hal 149.

${ }^{77}$ Ibid, hal 149.

78 Ibid, hal. 150
} 
penegasan tujuan partai proto Islam ini yaitu kemerdekaan nasional berdasarkan Islam. ${ }^{79}$ Kebijakan politik Hijrah kembali diperkuat pada kongres tahun 1931 ketika PSI, yang menurut Djaelani sejak tahun 1928 berubah menjadi PSII (Partai Sarekat Islam Indonesia), ${ }^{80}$ sedangkan menurut Noer dan Nasihin tahun $1930,{ }^{81}$ ketika merespon kebijakan pemerintah kolonial tentang rasionalisasi pejabat dalam rangka penghematan anggaran akibat krisis ekonomi yang menyebabkan peningkatan pengangguran. PSII menegaskan kembali perlunya hijrah dalam bidang ekonomi dan politik. ${ }^{82}$

Kebijakan politik Hijrah awalnya didukung penuh oleh seluruh anggota partai proto Islam tersebut. Namun mulai tahun 1936 muncul reactive sequences terhadap kebijakan itu khususnya pasca Tjokroaminoto wafat tahun 1934, ketika Agus Salim mengajukan proposal sebagai upaya membalikkan kembali PSII ke politik kooperasi dalam pernyataannya yang berjudul Pedoman Politik. ${ }^{83}$ Aksi ini memicu konflik internal setelah pada konggres tahun 1935 usulan Salim ditolak kelompok Abikusno dan ditegaskan lagi dalam Konggres PSII tahun 1936 di bawah pimpinan W. Wondoamiseno. Puncaknya Salim dicoret dari daftar pengurus partai proto tersebut. ${ }^{84}$ Hal ini mendorong Salim bersama Moehammad Roem dan Sangadji membentuk "Barisan Penyedar" pada 26 November 1936. ${ }^{85}$ Gerakan ini diketuai oleh Roem dan berencana menyebarkan idenya ke cabang-cabang lainnya. Aksi ini kemudian direspon Abikusno dengan melakukan konsolidasi internal pada Desember 1936 yang menginstruksikan semua anggota PSII mengakhiri polemik politik Hijrah serta melarang

\footnotetext{
${ }^{79}$ Anton Timur Djaelani, Gerakan Sarekat Islam : Kontribusinya pada Nasionalisme Indonesia, hal 123

80 Ibid, hal. 125.

${ }^{81}$ Deliar Noer, Deliar Noer, Gerakan Modern Islam di Indonesia 1900, hal 154 dan Nasihin, Sarekat Islam Mencari Ideologi 1924-1945, hal. 208.

82 Deliar Noer, Deliar Noer, Gerakan Modern Islam di Indonesia 1900, hal .160

${ }^{83}$ Anton Timur Djaelani, Gerakan Sarekat Islam : Kontribusinya pada Nasionalisme Indonesia, hal 132

${ }^{84} \mathrm{lbid}$, hal 132.

85 Ibid, hal 132.
} 
membantu rapat-rapat Barisan Penyedar. Tindakan Abikusno berlanjut pada Januari 1937 dengan menjatuhkan sanksi skorsing kepada para pemimpin Barisan Penyedar seperti Roem dan Sabirin. Puncak konflik terjadi bulan Februari ketika Salim, Sangadji, Sahirin, Roem beserta 24 tokoh Barisan Penyedar dipecat dari PSII. ${ }^{86}$

Pada tahun 1938 muncul reaksi dari kelompok Soekiman Wirjosandjojo, tokoh yang pernah keluar dari PSII dan membentuk PARII (Partai Islam Indonesia). Soekiman kembali memisahkan diri dari PSII tahun 1938 dan mendirikan Partai Islam Indonesia atau PII. ${ }^{87}$ Pembentukan PII tidak lepas dari ketidaksepakatan Sukiman, Wali Al fatah KH Mas Mansur terhadap politik Hijrah dan mengusulkan agar PSII kembali kepada politik kooperasi. Namun usulan tersebut ditolak, sehingga pada 4 Desember 1938 Soekiman dan kawan-kawan sepakat membentuk PII dengan ketuanya Raden Wiwoho. ${ }^{88}$

Reaksi lainnya dimotori oleh S.M. Kartosuwirjo melalui penulisan dan penyebaran brosur Hijrah yang tanpa berkonsultasi dengan Abikusno. Kartosuwirjo menolak penghentian penulisan dan penyebaran brosur tersebut sehingga dipecat dari PSII tahun 1939. Pemecatan ini memicu pembentukan Komite Pertahanan Kebenaran PSII oleh Kartosuwirjo bersama delapan cabang SI dari Jawa Tengah pada tahun 1940 dan menganggap sebagai Sarekat Islam yang otentik. ${ }^{89}$ Menyikapi komite tersebut, Abikusno memerintahkan semua anggota PSII menghentikan segala bentuk komunikasi dengan Kartosoewirjo yang dianggap melaksanakan keputusan konggres partai tahun 1938 secara sepihak, khususnya tentang pembentukan lembaga Suffah, tempat pendidikan, pelatihan, dan pengajaran bagi calon pemimpin Islam untuk mengimplementasikan Syariah Islam. $^{90}$

\footnotetext{
${ }^{86}$ Deliar Noer, Gerakan Modern Islam di Indonesia 1900-1942, hal 163

${ }^{87}$ Anton Timur Djaelani, Gerakan Sarekat Islam : Kontribusinya pada Nasionalisme Indonesia ,hal 134.

${ }^{88}$ Deliar Noer, Gerakan Modern Islam di Indonesia 1900-1942, hal 176-177.

89 Ibid, hal 166.

90 Ibid, hal 166.
} 
Konflik-konflik internal yang terjadi di PSII merupakan bentuk reactive sequences terhadap kebijakan politik Hijrah tahun 1923 dan menyebabkan pecahnya koherensi mereka sehingga meletakkan ke dalam jalur pembelahan atau cleaveage yang melemahkan organisasi. Hal ini diindikasikan merosotnya jumlah cabang-cabang PSII sejak tahun 1933-an. Noer mencatat meskipun jumlah anggota PSII meningkat dibandingkan tahun 1920-an, tetapi berjalan lambat. Di sisi lain jumlah cabang-cabang mengalami kemerosotan dari 135 pada tahun 1933 menjadi 100 pada tahun $1938 .{ }^{91}$

Kemorosotan jumlah anggota SI atau PSII berimplikasi terhadap ketidakberdayaan organisasi ini menghadapi represifitas pemerintah kolonial. Pasca keputusan politik Hijrah tahun 1923, penganti van Limburg Stirum yaitu Dirk Fork justru meneruskan kebijakan represif terhadap SI atau PSII. Pada tahun 1924 pemerintah kolonial membatasi ruang gerak beberapa tokoh PSII seperti Moeis di Pulau Jawa serta melarang Tjokroaminoto dan Salim menghadiri konggres se-Provinsi Kalimantan. ${ }^{92}$ Kebijakan tersebut berlanjut pada masa Gubernur Jenderal Jhr. B.D. de Jonge (1931-1936) yang mengeluarkan Ordonansi Sekolah Liar tahun 1932 dan 1933. Tahun 1934 de Jonge juga menerapkan larangan terbatas untuk mengadakan rapat atau Beperkt Vergader Verbod kepada PSII, termasuk Permi di Sumatera. Kebijakan tersebut diperkuat de Jonge pada tahun 1935 yang memberikan otoritas Gubernur Jenderal menentukan status partai apakah membahayakan atau tidak, melakukan pelarangan, serta membatasi rapat. Selain itu juga memberikan otoritas polisi untuk menghadiri rapat, dan jaksa agung untuk melarang orang menghadiri rapat partai, serta proses perijinan rapat harus diberikan kepada pejabat lima hari sebelum kegiatan berlangsung. Otoritas juga diberikan kepada kepala adat untuk mengawasi rapat; serta bupati, kepala adat dan kepala afdelling (asisten residen) untuk melarang rapat. ${ }^{93}$

91 Ibid, hal 167

92 Ibid, hal 222-223.

${ }^{93} \mathrm{Ibid}$, hal 225-226. 
Ketika de Jonge digantikan oleh Jhr. A.W.L Tjarda van Starkenbourgh Stachower, BVV dicabut namun hanya terbatas pada wilayah Bengkulu (untuk Permi) dan Minangkabau serta Tapanuli (untuk SI). Bahkan tindakan represif terhadap PSII tetap berlanjut. Puncak tindakan represif terjadi tahun 1940 ketika Perang Dunia II yang melibatkan juga Belanda mulai berkecamuk. Sebuah dekrit panglima militer dikeluarkan tanggal $10 \mathrm{Mei}$ 1940 yang memberlakukan keadaan darurat di Hindia Belanda. Dekrit tersebut melarang seluruh rapat politik yang bersifat umum, sementara rapat tertutup juga harus tunduk pada berbagai macam pembatasan termasuk pemberian otoritas pejabat setempat untuk melarangnya. Implikasi dari dekrit ini, banyak rapat-rapat PSII tidak bisa terlaksana bahkan dibubarkan. Selain itu banyak anggota partai yang ditangkap karena dituduh melanggar ketertiban dan ketentraman. Majalah PSII cabang Surakarta yaitu Pahlawan dilarang terbit oleh komandan militer setempat karena dianggap memprovokasi dan menganggu ketertiban serta ketentraman. ${ }^{94}$ Pemberlakuan dekrit tersebut telah menamatkan semua pergerakan nasional termasuk partai proto Islam PSII dan juga Permi. Dalam konteks path dependence berakhirnya kiprah politik SI atau PSII pada era kolonial Belanda seiring dengan ditetapkannya dekrit tahun 1940 merupakan outcomes atau hasil yang terkait momen critical juncture berupa kebijakan politik Hijrah tahun 1923.

\section{KESIMPULAN}

Dari uraian artikel ini dapat disimpulkan bahwa perkembangan partai proto Islam Indonesia pada era pra kemerdekaan yaitu Sarekat Islam (SI), yang kemudian bertransformasi menjadi PSI dan PSII, mengindikasikan sebuah path dependence repetetion yang mencakup tiga path dependence yang dipicu oleh tiga critical junctures. Setiap critical junctures memicu serangkaian urutan peristiwa lanjutan yang bersifat kausal, yang merupakan proses path dependence, baik reinforcement atau self reinforcing sequences

94 Ibid, hal. 228-229. 
maupun reactive sequences dan bermuara kepada final outcomes atau hasil akhir perkembangan organisasi SI.

Ketiga critical junctures merupakan keputusan politik agen-agen partai proto Islam tersebut dari alternatif-alternatif yang ditentukan oleh kondisi antesenden. Momen critical juncture pertama yaitu pendirian SDI pada 1911 oleh Haji Samanhudi memicu sejumlah reactive sequences yang merupakan proses path dependence pertama dan bermuara kepada hasil atau outcome legalisasi organisasi pada tahun 1916 sehingga memungkinkan SI berkembang pesat. Sedangkan path dependence kedua muncul dari critical juncture kebijakan displin partai tahun 1921 yang menghasilkan reactive sequences dengan pembentukan SI Merah tahun 1921 diikuti pembentukan Sarekat Rakyat di cabang-cabang SI Merah tahun 1923. Terbelahnya SI tersebut bermuara kepada hasil atau outcome merosotnya jumlah keanggotaan cabang-cabang. Dan path dependence ketiga dimunculkan critical juncture penetapan kebijakan politik Hijrah tahun 1923 yang diikuti proses reinforcement atau self reinforcing sequences berupa penguatan kebijakan pada konggres SI tahun 1924, 1927 dan 1931. Proses ini kemudian memicu reactive sequences dengan munculnya Barisan Penyedar, PII, dan Komite Pertahanan Kebenaran PSII yang menjadikan organisasi ini terbelah dan pengaruhnya merosot sehingga semakin lemah menghadapi kebijakan represif pemerintah kolonial hingga diberlakukannya UU darurat tahun 1940. 


\section{DAFTAR PUSTAKA}

\section{Jurnal}

Choia, Chang Gyu, Sugie Leeb, Heungsoon Kimb, dan Eun Yeong Seonga, "Critical junctures and path dependence in urban planning and housing policy: A review of greenbelts and New Towns in Korea's Seoul metropolitan area", Land Use Policy, No. 80,2019.

Mahoney, James, "Path-dependent Explanations of Regime Change : Central Amerika in Comparative Perspective, Studies in Comparative International Development", Spring ,Vol. 16, 2001.

-----, "Path Dependence in Historical Sociology”, Theory Social, Vol.29 (4), 2000.

\section{Buku}

Abdullah, Taufik, Sekolah dan Politik : Pergerakan Kaum Muda di Sumatra Barat, 1927-1933. Yogyakarta : Suara Muhammadiyah, 2018.

Amal, Ichasul (editor), Teori-teori Mutakhir Partai Politik. Yogyakarta : PT.Tiara Wacana, 1988.

Cresswell, John W, Penelitian Kualitatif dan Desain Riset : Memilih diantara lima pendekatan, terjemahan. Yogyakarta: Pustaka Pelajar, 2014.

Kahin, George Mc Turnan, Nasionalisme dan Revolusi Indonesia, (terjemahan Tim Komunitas Bambu). Jakarta : Komunitas Bambu, 2013.

Korver, A.P.E, Sarekat Islam, Gerakan Ratu Adil ?, terjemahan. Jakarta : PT Grafiti Pers, 1982.

Latif, Yudi ,Genaologi Intelegensia : Pengetahuan dan Kekuasaan Intelegensia Muslim Abab XX. Jakarta : Kencana Prenadamedia Group, 2013.

Mahoney, James ,The Legacies of Liberalism : Path Dependence and Political Regime in Central America. John Hopkins University Press, 2001.

McVey, Ruth. T, Kemunculan Komunisme Indonesia (terjemahan Tim Komunitas Bambu). Jakarta : Komunitas Bambu, 2010.

Nasihin, Sarekat Islam Mencari Ideologi 1924-1945. Yogyakarta : Pustaka Pelajar, 2012. 
Noer, Deliar, Gerakan Moderen Islam Di Indonesia 1900-1942. Jakarta : LP3ES, 1980.

Raharjo, Handri, Metomorfosis Sarekat Islam : Gerakan Politik Islam dan Munculnya Kesadaran Nasional. Yogyakarta : Media Pressindo, 2019.

Ricfleks, M.c ,A History of Modern Indonesia since c. 1200, Fourth Edition. USA : Palgrave Macmillan, 2008.

Strauss, Anselm dan Juliet Corbin, Dasar-Dasar Penelitian Kualitatif : tata langkah dan Teknik-teknik teorisasi data, terjemahan. Yogyakarta : Pustaka Pelajar, 2003,

Suminto, H. Aqib ,Politik Islam Hindia Belanda. Jakarta : LP3ES, 1985.

Yin, Robert K., Case Study Research Design and Methods, thrid edition. Sage Publication, 2003. 